\title{
A Bibliometric Analysis on Acidophilic Microorganism in Recent 30 Years
}

\author{
LI Si yuan ${ }^{1,2}$, Hao Chun bo ${ }^{1,2^{*}}$, Feng Chuan ping ${ }^{1,2}$, Wang Li hua ${ }^{1,2}$ and LIU Ying ${ }^{1,2}$ \\ ${ }^{1}$ Key Laboratory of Groundwater Circulation and Evolution of Ministry of Education, China
}

${ }^{2}$ School of Water Resources and Environment, Beijing 100083, China

"Corresponding author: Hao Chun bo, Key Laboratory of Groundwater Circulation and Evolution of Ministry of Education, China University of Geosciences, Beijing 100083, China, Tel: 13810803868; E-mail: mywenyan@gmail.com

Received date: April 22, 2014; Accepted date: May 22, 2014; Published date: May 29, 2014

Copyright: $\odot 2014$ Hao C, et al. This is an open-access article distributed under the terms of the Creative Commons Attribution License, which permits unrestricted use, distribution, and reproduction in any medium, provided the original author and source are credited.

\author{
Abstract \\ Objective: To evaluate the global scientific research and the tendencies on acidophilic organism during the past \\ 30 years. Studies in the acidophilic microorganism had significantly increased.
}

Methods: Articles related with the acidophilic organism were assessed by distribution of countries, institutes, journals using the method of bibliometric analysis.

Results: The results showed seven industrialized countries and four major developing countries were all listed in the top 20 most productive countries, which suggested economic conditions had an important effect on academic development. In addition, researchers in different institutions were more tending to cooperate. However, cooperation always occurred in the interior of the country. Through a synthetic analysis of the paper titles, author keywords and Keywords Plus, it revealed that "resistance to metal" attracted more attentions. Besides, this characteristic was also widely applied in bioleaching. At the level of research environment, "water" was the dominant position, such as acid mine drainage.

Conclusions: Study in the acidophilic microorganism had significantly increased. Cooperation had become the trend. Moreover, economic conditions had an important effect on academic development.

Keywords: Acidophilic microorganism; Bibliometric anaylsis; Resistance to metal; Bioleaching; Diversity

\section{Introduction}

Many microorganisms survive in the physically and geo-chemically extreme conditions, which have challenged the limits of life. These conditions include extremes of temperature, $\mathrm{pH}$, pressure, desiccation and others [1-3]. These microorganisms are termed as extremophiles. In recent decades, extremophiles have aroused great interest to researchers. Among them, acidophilic microorganisms are the ones that thrive in acidic environments with $\mathrm{pH}$ less than $3.0[4,5]$. They widely exist in acid mine drainage, bioleaching operation, and sulfuric hot spring [6-8]. Acidophilic microorganism not only can adapt to the environment of strong acid, but also can tolerate the high concentration of metal ions. Due to these special characteristics, they have been the hotspot in life science, and lots of microorganisms have been studied deeply, such as the Acidithiobacillus ferrooxidan [9]. Besides, acidophilic microorganisms have been widely applied in many respects, such as the bioremediation of heavy metal contaminated soil and water, extraction of enzyme, bio hydrometallurgy and others [10-12].

Scientific articles on acidophilic microorganism have demonstrated a rapid increase over the past several decades. A number of papers presenting the latest research achievements have been published in authoritative scientific journals such as Nature and Science $[13,14]$. Despite the high growth rate of publications, there have been few attempts to gather systematic data on this special microorganism. A common research tool for this analysis is the bibliometric method [15-17], which has already been widely applied in scientific production and research trends in kinds of topics, for example, global diversity [18], energy efficiency [19], agricultural technology [20], solid waste [21] biotechnology research [22,23]. The Science Citations Index Expanded (SCI-EXPANDED), from the Institute of Scientific Information (ISI) Web of Science databases, is the most important and frequently used source for a broad review of scientific accomplishment in all fields. Traditional bibliometric methods focus on citation and content analysis [24,25]. In recent years, analysis of word distribution of paper titles [26], KeyWords Plus [27], author keywords [28] in different periods has been used widely to get more information related to the research itself.

In this study, a bibliometric analysis of language, source country, institute and research field was performed to describe the importance of research on acidophilic microorganism. Besides, the distributions of keyword were also analyzed to study the research trends during the recent 30 years. Our conclusions not only provided a better understanding of global hotspot for researchers, but also clarified the future research direction on acidophilic microorganism.

\section{Data Sources and Methodology}

Data used in this research were based on the online database of the SCI, retrieved from the ISI Web of Science, Philadelphia, USA. According to Journal Citation Reports (JCR), it indexed 7391 major journals with citation references across 173 scientific disciplines in 2011. Besides, the reported impact factor (IF) of each journal was 
acquired from the 2011 JCR. Here, five search terms, including: "acidophilic organism", "acidophilic microorganism", "acidophilic bacteria" "acidophilic fungi" "acidophilic archaea" were used as keywords to search titles, keywords, document types, addresses and others during 1983-2012. Articles from England, Scotland, Northern Ireland and Wales were reclassified into the UK, and articles originating from Hong Kong and Taiwan were included in China. The collaboration type was determined by the addresses of the authors. The single-country publication was classified if the addresses of authors were in the same country. On the contrary, the internationally collaborative publication was assigned if authors were from different countries. In the same way, the single-institute publication was assigned if the addresses of researchers were from the same institute. The inter-institutionally collaborative publication was assigned if authors were from multiple institutes.

The words in titles were separated, and then conjunctions and prepositions such as "and", "the", "or", "for", "with", "by", and "on" were discarded, as they were meaningless in the further analysis. The ranks and frequencies of keywords between 1983 and 2012 were calculated in order to thoroughly analyze the variations of trends.

\section{Results and Discussion}

\section{Characteristics of publication outputs}

In this study, 10 document types were contained in the 2199 publications during the 30 -year study period, in which article was the most frequent type. Articles contributed a significant portion, $85 \%$ or 1873 of the total production. Another two documents were less significant, including proceedings paper $(6.5 \%)$ and review $(4.9 \%)$. The devotion of others was rare. As the dominant type of document, articles were used for further analysis. Ninety-eight percent of the journal articles were written in English. Another 12 languages also appeared. However, the proportion was less than $1 \%$. Obviously, English was the dominant language in acidophilic microorganism research.

The number of both of SCI documents and articles was analyzed and performed respectively in Figure 1 to understand the research trend in the 30 years. World academic publications had a notable growth after 1990, and there were two notable increases in the past three decades $(1990,2003)$. One important reason was that United States proposed the concept of the human genome in 1985, and in 1990 the 3-billion dollars project was formally founded. "Human Genome Project" intended to complete the entire human genome DNA sequence analysis in 15 years [29]. As a result, high-speed DNA sequencing methods came into being, which encouraged the study in microorganism on molecule level. Subsequently, high demand for lowcost sequencing had driven the development of high-throughput sequencing and several new methods for DNA sequencing were developed [30]. These techniques comprised the first of the "nextgeneration" sequencing methods, which was applied in many studies. Such as massively parallel signature sequencing (MPSS) published and marketed in 2000, 454 Life Sciences marketed in 2004 [31].

Based on the classification of subject categories in JCR 2011, the publication output data of acidophilic microorganism research were distributed into 109 SCI subject categories during 1983-2012. The most significant category was "Microbiology" (20\%), followed by "Biotechnology and Applied Microbiology" (13\%), "Biochemistry and Molecular Biology" (8.2\%) and "Environmental Sciences" (3.9\%).
"Microbiology" and "the Biotechnology and Applied Microbiology" were the two fastest growing subject categories, especially after 2001 (Figure 2), suggesting that the value of microorganism had been applied to the practice of production gradually, and molecular technology had been widely used in the study.

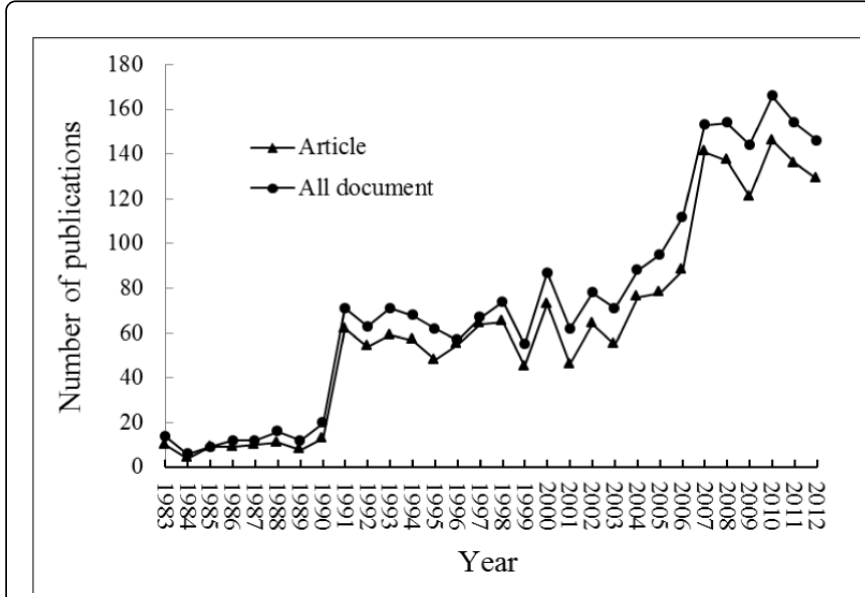

Figure 1: Trends of SCI-EXPANDED publications referring to acidophile during 1983-2012.

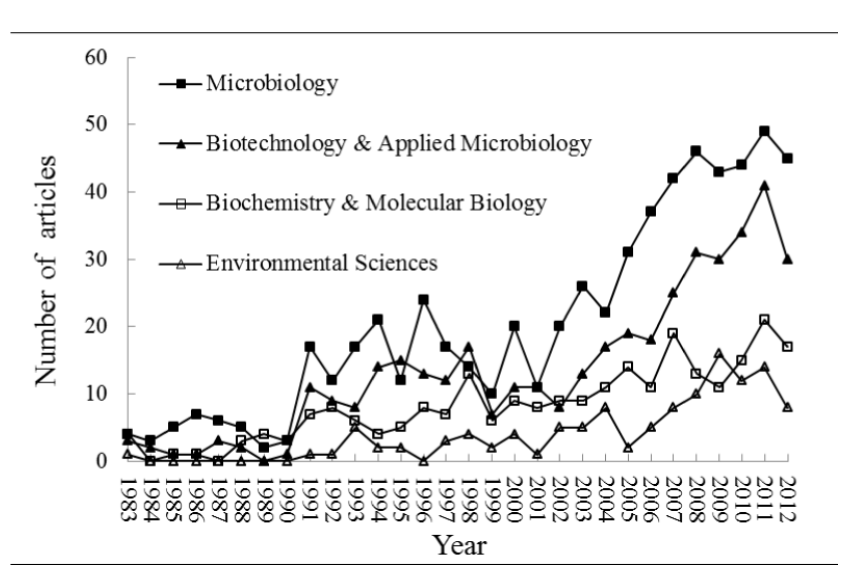

Figure 2: Comparison of the growth trends of the top four productive subject categories.

Articles were published in lots of journals, and the top 20 most productive journals were summarized in Table 1 . In this special study field, Applied and Environmental Microbiology published the most articles with $(107 ; 5.7 \%)$, followed by International Journal of Systematic and Evolutionary Microbiology with (62; 3.3\%), Hydrometallurgy with $(48 ; 2.6 \%)$. The average citation rate of journals in acidophilic microorganism was the most direct evidence for indicating the impacts of journal: the higher the citation was, the greater the impact was in this field. Besides, the average cited reference number per article also showed the importance of each article. International Journal of Systematic and Evolutionary Microbiology had the highest citation rate among the 20 journals. And Environmental Microbiology shared the highest average cited reference and the supreme IF. Those manifested the significant position of the two journals in this field. 
Citation: $\quad$ LI Si yuan, Hao Chun bo, Feng Chuan ping, Wang Li hua, LIU Ying (2014) A Bibliometric Analysis on Acidophilic Microorganism in Recent 30 Years . Int J Waste Resources 4: 147. doi:10.4172/2252-5211.1000147

Page 3 of 7

\begin{tabular}{|c|c|c|c|c|c|c|c|}
\hline Journal & TP & TP (\%) & IF & TC & $\mathrm{TC} / \mathrm{TP}$ & NR & NR/TP \\
\hline Applied and Environmental Microbiology & 107 & 5.7 & 3.829 & 3647 & 34.1 & 4218 & 39.4 \\
\hline $\begin{array}{l}\text { International Journal of Systematic and Evolutionary } \\
\text { Microbiology }\end{array}$ & 62 & 3.3 & 2.268 & 2127 & 34.3 & 2158 & 34.8 \\
\hline Hydrometallurgy & 48 & 2.6 & 2.027 & 511 & 10.6 & 1427 & 29.7 \\
\hline Extremophiles & 47 & 2.5 & 2.941 & 677 & 14.4 & 1647 & 35 \\
\hline Journal of Bacteriology & 35 & 1.9 & 3.825 & 732 & 20.9 & 1012 & 28.9 \\
\hline Microbiology & 35 & 1.9 & 0.718 & 99 & 2.8 & 657 & 18.8 \\
\hline FEMS Microbiology Letters & 35 & 1.9 & 2.044 & 649 & 18.5 & 643 & 18.4 \\
\hline Bioresource Technology & 24 & 1.3 & 4.98 & 189 & 7.9 & 777 & 32.4 \\
\hline Environmental Microbiology & 23 & 1.2 & 5.843 & 723 & 31.4 & 1210 & 52.6 \\
\hline Archives of Microbiology & 20 & 1.1 & 1.431 & 299 & 15 & 623 & 31.2 \\
\hline Geomicrobiology Journal & 20 & 1.1 & 2.017 & 313 & 15.7 & 839 & 42 \\
\hline World Journal of Microbiology \& Biotechnology & 18 & 1 & 1.532 & 113 & 6.3 & 457 & 25.4 \\
\hline FEMS Microbiology Ecology & 18 & 1 & 3.408 & 508 & 28.2 & 734 & 40.8 \\
\hline Systematic and Applied Microbiology & 17 & 0.9 & 3.366 & 469 & 27.6 & 495 & 29.1 \\
\hline Canadian Journal of Microbiology & 17 & 0.9 & 1.363 & 197 & 11.6 & 560 & 32.9 \\
\hline Minerals Engineering & 16 & 0.9 & 1.352 & 227 & 14.2 & 449 & 28.1 \\
\hline Microbiology-Sgm & 16 & 0.9 & 3.061 & 496 & 31 & 771 & 48.2 \\
\hline Bioscience Biotechnology and Biochemistry & 15 & 0.8 & 1.276 & 312 & 20.8 & 454 & 30.3 \\
\hline Microbial Ecology & 14 & 0.7 & 2.912 & 162 & 11.6 & 673 & 48.1 \\
\hline Biotechnology and Bioengineering & 14 & 0.7 & 3.946 & 268 & 19.1 & 411 & 29.4 \\
\hline
\end{tabular}

Table 1: The top 20 most productive journals based on the total number of articles. Note: TP: total number of articles, IF: 2011 ISI Impact factor, TC: total citation count, NR: cited reference count, TC/TP: average of citations in a paper, and NR/TP: the average cited reference count per article.

\section{Distribution of country articles}

All articles with author addresses could be used to analyze the distribution of country. In 1725 articles with author addresses, $71.6 \%$ were single-country publications, and only $28.4 \%$ were international. The top 20 most productive countries were summarized in Table 2, ranking with the way of number of journal articles and total citations. Among the 20 countries, the USA was the most productive country, including both single-country articles (214) and internationally collaborative articles (135). Germany ranked second with 201 and Japan ranked third with 190. Economic condition was related to the academic achievement: the seven industrialized countries (G7 group: the USA, Germany, Japan, France, the UK, Canada, and Italy) and four major developing countries ("BRIC": China, India, Brazil, and
Russia) were all included in the top 20 countries [32]. The same phenomenon was revealed in other bibliometric analyses [33,34]. Apart from the economic condition of different countries, one typical acid mine drainage located in USA, Iron Mountain Mine. As one of America's most toxic waste sites, it had been listed as a federal Superfund site since 1983, which made it be one research hot spot $[35,36]$. Between position of the "G7 group" and "BRIC", Spain was another high-producing country, because another typical acid mine drainage, Tinto River, which was notable for being very acidic ( $\mathrm{pH} 2)$ and its deep reddish hue, was located in Spain [37,38]. Another important message from these data in Table 2 was that single-country articles were the main trend in the study of acidophilic microorganism, especially in Japan, with a percentage of $90 \%$.

\begin{tabular}{|l|l|l|l|l|l|l|l|l|l|}
\hline Country & TP & SP & SP $(\%)$ & TC & TC/SP & CP & CP (\%) & TC & TC/CP \\
\hline USA & 349 & 214 & 61.3 & 7487 & 35 & 135 & 38.7 & 2649 & 19.6 \\
\hline Germany & 201 & 104 & 51.7 & 2141 & 20.6 & 97 & 48.3 & 2478 & 25.5 \\
\hline
\end{tabular}


Citation: $\quad$ LI Si yuan, Hao Chun bo, Feng Chuan ping, Wang Li hua, LIU Ying (2014) A Bibliometric Analysis on Acidophilic Microorganism in Recent 30 Years . Int J Waste Resources 4: 147. doi:10.4172/2252-5211.1000147

Page 4 of 7

\begin{tabular}{|c|c|c|c|c|c|c|c|c|c|}
\hline Japan & 190 & 171 & 90 & 2463 & 14.4 & 19 & 10 & 279 & 14.7 \\
\hline China & 158 & 118 & 74.7 & 676 & 5.7 & 40 & 25.3 & 459 & 11.5 \\
\hline UK & 152 & 81 & 53.3 & 2175 & 26.9 & 71 & 46.7 & 1658 & 23.4 \\
\hline Spain & 138 & 95 & 68.8 & 1546 & 16.3 & 43 & 31.2 & 570 & 13.3 \\
\hline Russia & 97 & 51 & 52.6 & 253 & 5 & 46 & 47.4 & 1474 & 32 \\
\hline France & 87 & 48 & 55.2 & 1128 & 23.5 & 39 & 44.8 & 750 & 19.2 \\
\hline Canada & 81 & 54 & 66.7 & 942 & 17.4 & 27 & 33.3 & 402 & 14.9 \\
\hline India & 81 & 65 & 80.2 & 855 & 13.2 & 16 & 19.8 & 68 & 4.3 \\
\hline Italy & 62 & 41 & 66.1 & 673 & 16.4 & 21 & 33.9 & 417 & 19.9 \\
\hline Chile & 54 & 27 & 50 & 391 & 14.5 & 27 & 50 & 391 & 14.5 \\
\hline Australia & 46 & 21 & 45.7 & 350 & 16.7 & 25 & 54.3 & 311 & 12.4 \\
\hline Netherlands & 40 & 20 & 50 & 509 & 25.5 & 20 & 50 & 295 & 14.8 \\
\hline South Korea & 38 & 18 & 47.4 & 158 & 8.8 & 20 & 52.6 & 154 & 7.7 \\
\hline Sweden & 35 & 13 & 37.1 & 284 & 21.8 & 22 & 62.9 & 313 & 14.2 \\
\hline Brazil & 33 & 26 & 78.8 & 113 & 4.3 & 7 & 21.2 & 103 & 14.7 \\
\hline South Africa & 30 & 19 & 63.3 & 305 & 16.1 & 11 & 36.7 & 205 & 18.6 \\
\hline Finland & 25 & 10 & 40 & 98 & 9.8 & 15 & 60 & 112 & 7.5 \\
\hline Belgium & 21 & 11 & 52.4 & 107 & 9.7 & 10 & 47.6 & 130 & 13 \\
\hline
\end{tabular}

Table 2: Top 20 most productive countries based on the total number of articles. Note: TP: total number of articles, SP: single country articles, CP: internationally collaborative articles, TC: total citation count.

\section{Distribution of institute analysis}

The distributions of different institutes were evaluated by the affiliation of at least one author. Of all articles with author addresses, $43.2 \%$ were single-institute articles and $56.8 \%$ were interinstitutionally collaborative articles, suggesting that study of acidophilic microorganism called for teamwork among institutes. The top 20 most productive institutes were summarized in Table 3, in which the distribution was equal. Three were from China, the USA, the UK, Spain, two were from Russia, and one was from Germany, Japan, France, Sweden, India, Chile. The Russian Academy of Sciences had the most total articles (94), including 12 independent articles and 82 inter-institutionally collaborative articles, followed by Central South University, University of California, Berkeley, University of Chile and two institutes from Spain, Spanish National Research Council and the University of Murcia. It should be noted that
University of California, Berkeley had the highest average citation rate, including independent articles (238) and inter-institutionally collaborative articles (35.6). It suggested that University of California, Berkeley had a fairly high status in this academic field. It should be noted that the university was close to the typical acid mine drainage, Iron Mountain Mine, which was mentioned above. Another observation could be obtained from Table 3 that only four institutes ( 2 UK, 1 Spain, 1 India) had more independent articles than interinstitutionally collaborative articles. There were also another two institutes, Oak Ridge National Laboratory and Max Planck Institute for Terrestrial Microbiology that only published the interinstitutionally collaborative articles. Moreover, the average citation rate was relatively high. These proved that the academic communities of acidophilic microorganisms were more tending to cooperation.

\begin{tabular}{|l|l|l|l|l|l|l|l|l|l|}
\hline Institute & TP & SP & SP (\%) & TC & TC/SP & CP & CP (\%) & TC & TC/CP \\
\hline Russian Academy of Sciences, Russia & 94 & 12 & 12.8 & 118 & 9.8 & 82 & 87.2 & 1551 & 18.9 \\
\hline Central South University, China & 48 & 11 & 22.9 & 75 & 6.8 & 37 & 77.1 & 158 & 4.3 \\
\hline University of California, Berkeley, USA & 42 & 4 & 9.5 & 952 & 238 & 38 & 90.5 & 1351 & 35.6 \\
\hline University of Chile, Chile & 39 & 7 & 17.9 & 107 & 15.3 & 32 & 82.1 & 505 & 15.8 \\
\hline
\end{tabular}


Citation: $\quad$ LI Si yuan, Hao Chun bo, Feng Chuan ping, Wang Li hua, LIU Ying (2014) A Bibliometric Analysis on Acidophilic Microorganism in Recent 30 Years . Int J Waste Resources 4: 147. doi:10.4172/2252-5211.1000147

Page 5 of 7

\begin{tabular}{|l|l|l|l|l|l|l|l|l|l|}
\hline Spanish National Research Council, Spain & 39 & 9 & 23.1 & 242 & 26.9 & 30 & 76.9 & 15 & 0.5 \\
\hline The University of Murcia, Spain & 36 & 20 & 55.6 & 578 & 28.9 & 16 & 44.4 & 164 & 10.3 \\
\hline Chinese Academy of Sciences, China & 36 & 7 & 19.4 & 29 & 4.1 & 29 & 80.6 & 102 & 3.5 \\
\hline Okayama University, Japan & 27 & 13 & 48.1 & 142 & 10.9 & 14 & 51.9 & 242 & 17.3 \\
\hline Autonomous University of Madrid, Spain & 26 & 4 & 15.4 & 46 & 11.5 & 22 & 84.6 & 313 & 14.2 \\
\hline University of Warwick, UK & 25 & 14 & 56 & 491 & 35.1 & 11 & 44 & 425 & 38.6 \\
\hline Umea University, Sweden & 24 & 5 & 20.8 & 144 & 28.8 & 19 & 79.2 & 212 & 11.2 \\
\hline Lomonosov Moscow State University, Russia & 24 & 8 & 33.3 & 19 & 2.4 & 16 & 66.7 & 166 & 10.4 \\
\hline National Centre for Scientific Research, France & 23 & 8 & 34.8 & 199 & 24.9 & 15 & 65.2 & 323 & 21.5 \\
\hline The University of Wales, UK & 22 & 16 & 72.7 & 440 & 27.5 & 6 & 27.3 & 228 & 38 \\
\hline Indian Institute of Chemical Technology, India & 22 & 20 & 90.9 & 580 & 29 & 2 & 9.1 & 16 & 8 \\
\hline Bangor University, UK & 21 & 7 & 33.3 & 71 & 10.1 & 14 & 66.7 & 134 & 9.6 \\
\hline The Ohio State University, USA & 19 & 2 & 10.5 & 54 & 27 & 17 & 89.5 & 161 & 9.5 \\
\hline $\begin{array}{l}\text { Chinese Academy of Agricultural Sciences, } \\
\text { China }\end{array}$ & 19 & 1 & 5.3 & 12 & 12 & 18 & 94.7 & 182 & 10.1 \\
\hline Oak Ridge National Laboratory, USA & 18 & - & - & 0 & - & 18 & 100 & 398 & 22.1 \\
\hline $\begin{array}{l}\text { Max Planck Institute for Terrestrial } \\
\text { Microbiology, Germany }\end{array}$ & 16 & - & - & 0 & - & 16 & 100 & 1181 & 73.8 \\
\hline
\end{tabular}

Table 3: Top 20 most productive institutes based on the total number of articles. Note: TP: total number of articles, SP: single institute articles, $\mathrm{CP}$ : inter-institutionally collaborative articles, TC: total citation count, _-: no articles.

\section{Hot issues}

The most important information, which the author expected to express to readers, was presented in the title, keywords and KeyWords Plus. In order to analyze the three separated parts synthetically, the synonymic single words and congeneric phrases were summed and grouped into categories. In this way, the analysis of historical development of science could be more complete and precise, and the new direction about this field could be found. A new method named "word cluster analysis" had been applied to analyze the research trends in risk assessment [39] and nitrate removal. All words included in Figures 3 and 4 contained their plural forms and other transformations, as well as words with the similar meanings.

Research trends in acidophilic microorganism were separated into two categories: research hotspot and research environment. In terms of the research hotspot, the "resistance to metal" was the most predominant for 20 years (Figure 3). Tolerance to various kinds of heavy metal had been analyzed in recent years, such as $\mathrm{Fe}, \mathrm{Cu}, \mathrm{Al}, \mathrm{Zn}$. This characteristic had been widely applied to bioleaching to increase the purity of mixed ore [40-42]. In addition, "diversity" became the second research branch with a fast speed, since the application of cultivation-independent molecular techniques becoming more mature, such as FISH, PCR-DGGE $[43,44]$. The number of the articles using molecular biology techniques during 2005-2012 was half of the total number in 30 years. On the contrary, because of the limitation of technical means and the difficulty in controlling the micro-world, the development of "enzyme" and "culture" was relatively slow. Therefore, the study in acidophilic microorganism focused on the resistance to metal and diversity, which had more practical value and substantial benefit.

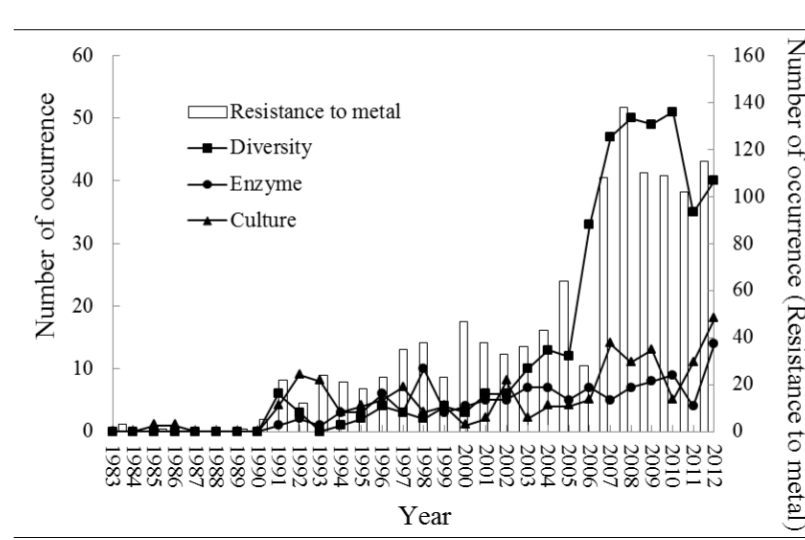

Figure 3: Comparison of the trends of research hotspots, resistance to metal, diversity, enzyme, culture.

Research trend of kinds of environments had been showed in Figure 4, including "water", "soil", "hot spring" and "leaching heap". The difference between four environments became obvious after 2006, because of a rapid increase in the "water" and "bioleaching heap". First of all, "water" was the most wide study environment, such as acid mine drainage. The research in "water" reached a peak point in 2008. Referring to the increasing trend of "bioleaching heap", the main 
reason was that people realized the value of acidophilic microorganism in industry. France was the earliest one, trying to leaching gold in ores by bacteria in 1964, and achieved encouraging results. Subsequently, bioleaching developed gradually, and became industrialized. The industrialization reached an obvious peak point in 2008. Although "soil" was not main living environment, acidophilic microorganism was abundant in soil which was proved in lots of articles. The field around the acid mine drainage was contaminated by the acid water, and became exclusively suitable for this special microorganism. On the contrary, "hot spring" acted as the original living environment, but articles about "hot spring" were rare.

Another result should be noted that there was a decrease after 2007, including "water", "bioleaching heap", "soil", and even "resistance to metal", "diversity". All of this may be a direct result of economic crisis happened in 2007, which made the fund for scientific research have an obvious shrinkage in the whole world. To a large extent, the economic situation provided a solid foundation to the research.

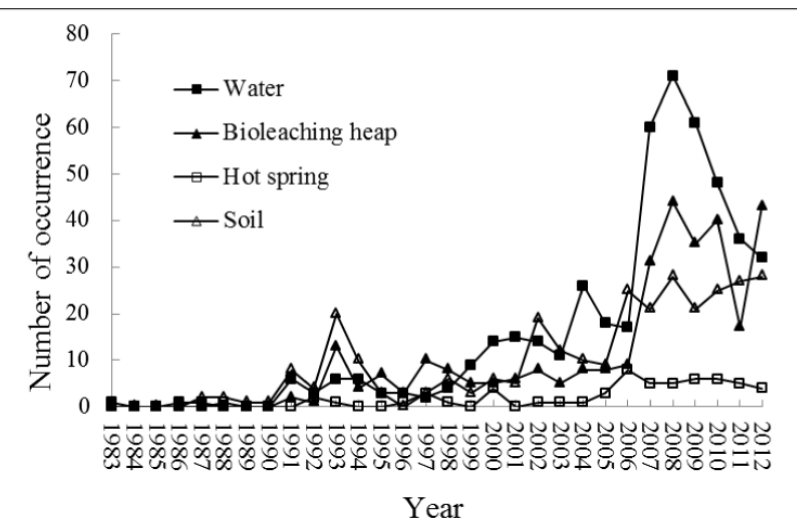

Figure 4: Comparison of the trends of research environment, water, leaching, hot spring, soil.

\section{Conclusions}

Based on the databases of acidophilic microorganism listed in SCIEXPANDED, some significant points on the worldwide research performance were studied using bibliometric analysis during the 30 years. The following conclusions were summarized from this study:

Study in the acidophilic microorganism had significantly increased in the last 30 years, especially in the year 2003-2012.

1873 articles have been distributed into 109 SCI subject categories. "Microbiology" and "the Biotechnology and Applied Microbiology" were the two fastest growing subject categories, suggesting that the value of microorganism had been applied to the practice of production gradually.

At the country level, $71.6 \%$ were single-country publications, and $28.4 \%$ were international articles. The USA had the most dominant position including the most total articles, single-country articles and internationally collaborative articles. Besides, economic condition was related to the academic achievement. The G7 and the BRIC were listed in the top 20 most productive countries.

In the analysis of distribution of institute, $43.2 \%$ of all articles were single-institutional and $56.8 \%$ were inter-institutional. In the top 20 most productive institutes, only four institutes had more independent articles than inter-institutionally collaborative articles, and another two institutes only published the inter-institutionally collaborative articles. These proved that the academic communities of acidophilic microorganisms were more tending to cooperation.

Using a new bibliometric method - "word cluster analysis" - found that "resistance to metal" and "diversity" will continue to be the leading research hotspots. Eventually, "water" will be the main research environment.

\section{Acknowledgements}

This research was supported by grants from the National Science Foundation of China (40802059), the Fundamental Research Funds for the Central Universities (2010ZD03, 2011YXL035).

\section{References}

1. Garcia-Gonzalez L, Rajkovic A, Geeraerd AH, Elst K, Ginneken LV, et al. (2010) The development of Escherichia coli and Listeria monocytogenes variants resistant to high-pressure carbon dioxide inactivation. Letters in Applied Microbiology 50: 653-656.

2. Sharma A, Kawarabayasi Y, Satyanarayana T (2012) Acidophilic bacteria and archaea: acid stable biocatalysts and their potential applications. Extremophiles 16: 1-19.

3. Chen MM, Liu QH, Xin GR, Zhang JG (2013) Characteristics of lactic acid bacteria isolates and their inoculating effects on the silage fermentation at high temperature. Lett Appl Microbiol 56: 71-78.

4. Schleper C, Puehler G, Holz I, Gambacorta A, Janekovic D, et al. (1995) Picrophilus gen nov fam nov: a novel aerobic heterotrophic Thermoacidophilic genus and family comprising archaea capable of growth around pH-0. Journal of Bacteriology 177: 7050-7059.

5. Rothschild LJ, Mancinelli RL (2001) Life in extreme environments. Nature 409: 1092-1101.

6. Hao C, Wang L, Gao Y, Zhang L, Dong H (2010) Microbial diversity in acid mine drainage of Xiang Mountain sulfide mine, Anhui Province, China. Extremophiles 14: 465-474.

7. Ding JN, Zhang R, Yu Y, Jin D, Liang C, et al. (2011) A novel acidophilic, thermophilic iron and sulfur-Oxidizing archaeon Isolated from a hot spring of TengChong YunNan China. Brazilian Journal of Microbiology 42: 514-525.

8. Ruiz LM, Castro M, Barriga A, Jerez CA, Guiliani N (2012) The extremophile Acidithiobacillus ferrooxidans possesses a c-di-GMP signalling pathway that could play a significant role during bioleaching of minerals. Letters in Applied Microbiology 54: 133-139.

9. Ramírez P, Guiliani N, Valenzuela L, Beard S, Jerez CA (2004) Differential protein expression during growth of Acidithiobacillus ferrooxidans on ferrous iron, sulfur compounds, or metal sulfides. Appl Environ Microbiol 70: 4491-4498.

10. Karelová E, Harichová J, Stojnev T, Pangallo D, Ferianc P (2011) The isolation of heavy-metal resistant culturable bacteria and resistance determinants from a heavy-metal-contaminated site. Biologia 66: 18-26.

11. Hallberg KB, Johnson DB (2005) Microbiology of a wetland ecosystem constructed to remediate mine drainage from a heavy metal mine. Sci Total Environ 338: 53-66.

12. Wang H, Luo H, Li J, Bai Y, Huang H, et al. (2010) An alphagalactosidase from an acidophilic Bispora sp. MEY-1 strain acts synergistically with beta-mannanase. Bioresour Technol 101: 8376-8382.

13. Bräuer SL, Cadillo-Quiroz H, Yashiro E, Yavitt JB, Zinder SH (2006) Isolation of a novel acidiphilic methanogen from an acidic peat bog. Nature 442: 192-194.

14. Baker BJ, Tyson GW, Webb RI, Flanagan J, Hugenholtz P, et al. (2006) Lineages of acidophilic archaea revealed by community genomic analysis. Science 314: 1933-1935. 
Citation: $\quad$ LI Si yuan, Hao Chun bo, Feng Chuan ping, Wang Li hua, LIU Ying (2014) A Bibliometric Analysis on Acidophilic Microorganism in Recent 30 Years . Int J Waste Resources 4: 147. doi:10.4172/2252-5211.1000147

Page 7 of 7

15. Raan AFJ (1996) Advanced bibliometric methods as quantitative core of peer review based evaluation and foresight exercises. Scientometrics 35: 397-420.

16. Narin F, Hamilton KS (1996) Bibliometric performance measures. Scientometrics 36: 293-310.

17. Wang X, Wang Z, Xu S (2013) Tracing scientist's research trends realtimely. Scientometrics 2013 95: 717-729.

18. Vergidis PI, Karavasiou AI, Paraschakis K, Bliziotis IA, Falagas ME (2005) Bibliometric analysis of global trends for research productivity in microbiology. Eur J Clin Microbiol Infect Dis 24: 342-346.

19. Du HB, Wei LX, Brown MA, Wang YY, Shi Z (2013) A bibliometric analysis of recent energy efficiency literatures: an expanding and shifting focus. Energy Efficiency 6: 177-190.

20. Lee LC, Lee YY, Liaw YC (2012) Bibliometric analysis for development of research strategies in agricultural technology: the case of Taiwan. Scientometrics 93: 813-830.

21. Fu HZ, Ho YS, Sui YM, Li ZS (2010) A bibliometric analysis of solid waste research during the period 1993-2008. Waste Manag 30: 2410-2417.

22. Bajwa RS, Yaldram K (2013) Bibliometric analysis of biotechnology research in Pakistan. Scientometrics 95: 529-540.

23. Costa BMG, Pedro EDS, Macedo GRD (2013) Scientific collaboration in biotechnology: the case of the northeast region in Brazil. Scientometrics 95: 571-592.

24. Khan MA, Ho YS (2012) Top-cited articles in environmental sciences: merits and demerits of citation analysis. Sci Total Environ 431: 122-127.

25. Ahmed T, Johnson B, Oppenheim C, Peck C (2004) Highly cited old papers and the reasons why they continue to be cited. Part II. The 1953 Watson and Crick article on the structure of DNA. Scientometrics 61: 147-156.

26. Li J, Wang MH, Ho YS (2011) Trends in research on global climate change: a Science Citation Index Expanded-based analysis. Global and Planetary Change 77: 13-20.

27. Qin J (2000) Semantic similarities between a keyword database and a controlled vocabulary database: An investigation in the antibiotic resistance literature. Journal of the American Society for Information Science 51: 166-180.

28. Ugolini D, Cimmino MA, Casilli C, Mela GS (2001) How the European Union writes about ophthalmology. Scientometrics 52: 45-58.

29. DeLisi C (2008) Meetings that changed the world: Santa Fe 1986: Human genome baby-steps. Nature 455: 876-877.

30. Hall N (2007) Advanced sequencing technologies and their wider impact in microbiology. J Exp Biol 210: 1518-1525.
31. Mardis ER (2008) Next-generation DNA sequencing methods. Annu Rev Genomics Hum Genet 9: 387-402.

32. Yang LY, Yue T, Ding JL, Han T (2012) A comparison of disciplinary structure in science between the G7 and the BRIC countries by bibliometric methods. Scientometrics 93: 497-516.

33. Xie SD, Zhang J, Ho YS (2008) Assessment of world aerosol research trends by bibliometric analysis. Scientometrics 77: 113-130.

34. Huang WL, Zhang BG, Feng CP, Li M, Zhang J (2012) Research trends on nitrate removal: a bibliometric analysis. Desalination and Water Treatment 50: 67-77.

35. Bond PL, Smriga SP, Banfield JF (2000) Phylogeny of microorganisms populating a thick subaerial predominantly lithotrophic biofilm at an extreme acid mine drainage Site. Applied and Environmental Microbiology 66: 3842-3849.

36. Edwards KJ, Bond PL, Gihring TM, Banfield JF (2000) An archaeal ironoxidizing extreme acidophile important in acid mine drainage. Science 287: 1796-1799.

37. Sanchez-Andrea I, Knittel K, Amann R, Amils R,Sanz JL (2012) Quantification of Tinto River sediment microbial communities: importance of sulfate-reducing bacteria and their role in attenuating acid mine drainage. Applied Environmental Microbiology 78: 4638-4645.

38. Cánovas CR, Olias M, Vazquez-Suñé E, Ayora C, Miguel Nieto J (2012) Influence of releases from a fresh water reservoir on the hydrochemistry of the Tinto River (SW Spain). Sci Total Environ 416: 418-428.

39. Mao N, Wang MH, Ho YS (2010) A bibliometric study of the trend in articles related to risk assessment published in Science Citation Index. Human and Ecological Risk Assessment: An International Journal 16: 801-824.

40. Küsel K, Dorsch T (2000) Effect of Supplemental Electron Donors on the Microbial Reduction of Fe(III), Sulfate, and $\mathrm{CO}(2)$ in Coal MiningImpacted Freshwater Lake Sediments. Microb Ecol 40: 238-249.

41. Fischer J, Quentmeier A, Gansel S, Sabados V, Friedrich CG (2002) Inducible aluminum resistance of Acidiphilium cryptum and aluminum tolerance of other acidophilic bacteria. Arch Microbiol 178: 554-558.

42. Mangold S, Potrykus J, Björn E, Lövgren L, Dopson M (2013) Extreme zinc tolerance in acidophilic microorganisms from the bacterial and archaeal domains. Extremophiles 17: 75-85.

43. Sun FL, Wang YS, Wu ML, Wang YT, Li QP (2011) Spatial heterogeneity of bacterial community structure in the sediments of the Pearl River estuary. Biologia 66: 574-584.

44. Lakatošová M, Holecková B (2007) Fluorescence in situ hybridisation. Biologia 62: 243-250. 